\title{
Investigation of stone-hard-soil formation from AC corrosion of cathodically protected pipeline
}

Junker, Andreas; Belmonte, Louise Josefine; Kioupis, Nick; Nielsen, Lars Vendelbo; Moller, Per

Published in:

Materials and Corrosion

Link to article, DOI:

10.1002/maco.201709947

Publication date:

2018

Document Version

Peer reviewed version

Link back to DTU Orbit

Citation (APA):

Junker, A., Belmonte, L. J., Kioupis, N., Nielsen, L. V., \& Moller, P. (2018). Investigation of stone-hard-soil formation from AC corrosion of cathodically protected pipeline. Materials and Corrosion, 69(9), 1170-1179. https://doi.org/10.1002/maco.201709947

\section{General rights}

Copyright and moral rights for the publications made accessible in the public portal are retained by the authors and/or other copyright owners and it is a condition of accessing publications that users recognise and abide by the legal requirements associated with these rights.

- Users may download and print one copy of any publication from the public portal for the purpose of private study or research.

- You may not further distribute the material or use it for any profit-making activity or commercial gain

- You may freely distribute the URL identifying the publication in the public portal 


\section{Article type: Article}

\section{Investigation of Stone-hard-soil Formation from AC Corrosion of Cathodically Protected Pipeline}

Andreas Junker ${ }^{*}$, Louise Josefine Belmonte, Nick Kioupis, Lars Vendelbo Nielsen, Per Møller

Andreas Junker

Technical University of Denmark, Produktionstorvet, B425, 2800 Kgs. Lyngby, Denmark/MetriCorr, Toerringvej 7, 2610 Roedovre, Denmark *andjun@mek.dtu.dk/ajh@metricorr.com

Louise Josefine Belmonte

Technical University of Denmark. Nordvej, B119, 2800 Kgs. Lyngby, Denmark

Nick Kioupis

DESFA. 357-359, Mesogion Ave. 15231 Halandri, Greece

Lars Vendelbo Nielsen

MetriCorr, Toerringvej 7, 2610 Roedovre, Denmark

Per Møller

Technical University of Denmark. Nils Koppels Allé, B404, 2800 Kgs. Lyngby, Denmark

Abstract

A stone-hard-soil structure was observed on a metallic pipeline under cathodic protection and subject to alternating current corrosion at a coating defect. Using x-ray diffraction, energy dispersive x-ray spectroscopy, ion-chromatography and inductively coupled plasma optical emission spectroscopy, the stone-hard-soil was characterised as being enriched in $\mathrm{NaCl}$. Local alkalisation following the cathode reactions caused precipitation of calcite, believed to be partly responsible for the stability of the structure. Very close to the corrosion site at the 


\section{WILEY-VCH}

epicentre, calcite and quartz was depleted, possibly owing to an extremely high pH. Formation of cement-like minerals and corrosion products is observed.

Keywords: Alternating current (AC), Cathodic protection, Pipeline, Carbon steel, Calcareous deposition, X-ray diffraction

\section{Introduction}

AC corrosion is well known from pipelines under cathodic protection subject to AC perturbations, e.g. induced from high voltage transmission lines. [1,2] The corrosion attack is reported by several authors to be localised at coating defects and create a hard dome of soil and corrosion products over the corrosion site, sometimes referred to as corrosion stone or stone-hard-soil. [1,3-6] While AC corrosion has been extensively investigated in the past 30 years, only little interest has been given to the stone-hard-soil formations, though it can provide important information on the corrosion conditions. Stalder reported weak alkalinity (9.3-9.5) of aqueous extracts of a stone-hard-soil sample, and X-ray diffraction revealed large concentrations of goethite $\alpha-\mathrm{FeOOH}$, wegscheiderite $\mathrm{Na}_{2} \mathrm{CO}_{3} \times 3 \mathrm{NaHCO}_{3}$ and $\mathrm{KNaSO}_{4}$. [3,7] In another study, Stalder reported that lime was depleted from the close vicinity of the coating defect. [8] Simon reported a pH as high as 11 at the pipe surface under the precipitated corrosion product. [1] Linhardt \& Ball reported increased Na concentrations in a stone-hard-soil formation as well as the presence of sodium carbonate and sodium bicarbonate owing to large cathodic activity. [4] Furthermore they attributed a 'mixed' appearance of the stone-hard-soil to evolution of gas bubbles at the coating defect due to the cathode reaction under anaerobic conditions (1) which also produces alkalinity. The main corrosion product they discovered was magnetite, $\mathrm{Fe}_{3} \mathrm{O}_{4}$.

$2 \mathrm{H}_{2} \mathrm{O}+2 \mathrm{e}^{-} \rightarrow \mathrm{H}_{2}(g)+2 \mathrm{OH}^{-}$ 


\section{WILEY-VCH}

A well-documented theory for AC corrosion is that an increasingly alkaline environment at the steel surface will reduce the electric resistance to remote earth and increase the AC and DC current flowing through the coating defect at constant AC and DC voltages. [9-10] Adversely if earth alkaline metals such as Ca and Mg are present, these might cause the precipitation of insoluble carbonates and hydroxides at high $\mathrm{pH}$, possibly covering the coating defect with an insulating layer and decreasing the currents and corrosion rate. [8,11] Some authors speculate that the formed stone-hard-soil 'tubercle' may be of lower resistivity and thus behave as an antenna of increased surface area that will pick up both AC and DC currents in the soil and thus escort an autocatalytic corrosion attack by increasing current densities. [6] Enhancement of the cathode reaction (1) by faradaic rectification of the AC current plays a major role in comparison to pure DC conditions. [12-15] The DC current may be orders of magnitude higher than at regular $\mathrm{CP}$, and thus the alkalisation is more pronounced in AC corrosion cases.

According to the EN 15280:2013 standard, critical current density values for AC corrosion are $\mathrm{J}_{\mathrm{DC}}=1 \mathrm{~A} \mathrm{~m}^{-2}$ and $\mathrm{J}_{\mathrm{AC}}=30 \mathrm{~A} \mathrm{~m}^{-2}$, above which AC corrosion is likely to occur. Smaller coating defects are thus more vulnerable to AC corrosion

The stone-hard-soil sample investigated in this study is shown in Figure 1. It is half of the semi spherical structure that develops at a coating defect on a pipeline subject to cathodic protection and an AC perturbation. The sample is split in the direction of the pipeline. It is clear that the structure is spherical around a corrosion site (Figure 1a-c) with a clearly altered appearance towards the corrosion site in Figure 1d.

The pipeline on which the structure was discovered was a $\varnothing=76.2 \mathrm{~cm}$ (30 inches) low alloy carbon steel with an initial wall thickness of $12.7 \mathrm{~mm}$ and a three-layer extruded polyethylene coating, transporting dry natural gas. It was buried in Ca rich clayey soil in the Mediterranean region in Southern Europe. The on-potential was kept at approx. $\mathrm{E}_{\text {on }}=-1.3 \mathrm{~V}$ vs. a $\mathrm{Cu} / \mathrm{CuSO}_{4}$ 


\section{WILEY-VCH}

standard reference electrode (CSE) during the service life of the pipeline. During the first 4-5 years of service an induced AC voltage in the order of $U_{A C}=13 \mathrm{~V}(25 \mathrm{~V}$ max $)$ was recorded but after installation of a capacitive AC mitigation device, this was reduced to average values of 0.4-1.0 V (3-4 V max) during the following 15 years of service. The corrosion site was discovered in 2012 during a magnetic flux leakage (MFL) pigging of the pipe and excavated in 2014. The corrosion site was localized at a 20x10 mm coating defect, with a coating lift-off exposing a 30x15 mm area of the steel, typical for AC corrosion. The thickness reduction was measured to be $29 \%$, yielding an average corrosion rate of $\sim 190 \mu \mathrm{m}$ per year over the service life. It is assumed that the corrosion rate was higher during the first years of high alternating voltage, but it is known that AC corrosion in similar soils can be critical even at highly reduced alternating voltages. [16]

A meticulous investigation of the stone-hard-soil offers valuable insight into the long term evolving environment around a coating defect on a pipeline subject to AC corrosion.

\section{Materials and methods / Experimental}

The stone-hard-soil sample was handled in air, i.e. not in a protective atmosphere, prior to analysis. Fe(II) oxides which may have been present during corrosion can thus not be characterized in the present analysis due to oxidation to Fe(III) species.

Powder samples from the stone-hard-soil were extracted using a Ø6 mm drill along a straight line at distances of $0,1,2,4,6,8$ and $10 \mathrm{~cm}$ from the corrosion site on the cross-section shown in Figure 1a, assuming approximately spherical uniformity in the stone-hard-soil. Additional two samples were taken from a reference soil (REF) excavated from nearby unaffected soil close to the pipeline.

Samples (0-10, REF) were analysed with a Panalytical X'Pert Pro X-ray Diffractometer (XRD) using $\mathrm{CuK} \alpha$ radiation and $2 \theta=3-66^{\circ}$ for two hours for each sample. The powders 


\section{WILEY-VCH}

were ground to a particle size $<45 \mu \mathrm{m}$ in an agate mortar prior to analysis. Furthermore, a scrape off of the white powdery phase shown in Figure 1d was analysed by XRD. Samples (0-10, REF) were analysed for chemical composition using energy dispersive X-ray spectroscopy (EDS) in a JEOL JSM-5900 scanning electron microscope (SEM). Powder was evenly dispersed on a conductive carbon pad and carbon coated, and an approximate area of $250 \cdot 10^{3} \mu \mathrm{m}^{2}$ was measured at two different locations for each sample.

Samples (0-6, 10, REF) were analysed for chemical composition by inductively coupled plasma optical emission spectroscopy (ICP-OES) using the US EPA 3052 method. The $8 \mathrm{~cm}$ sample was excluded since no additional information was expected from this region.

Samples (1-10, REF) were analysed for $\mathrm{pH}$ value by dissolving $0.40 \mathrm{~g}$ of dry material in $2 \mathrm{~mL}$ of reagent water in a 1:5 soil to water relationship, due to the small amount of sample material. Insufficient sample material from the $0 \mathrm{~cm}$ location was available for a $\mathrm{pH}$ measurement. The solutions were ultrasonically mixed for 5 minutes to ensure full dissolution of all relevant species and subsequently left to segregate in a solid and liquid phase for 1 hour before $\mathrm{pH}$ measurement. The $\mathrm{pH}$ was measured using a Radiometer PHC3359-8 Combination pH Electrode until a steady value could be read.

The soil resistivity of the stone-hard-soil as well as the reference soil was measured in a 80 $\mathrm{cm}^{3}$ M.C. Miller soil box using the 4 electrode method. Sample material spanning from the 2$10 \mathrm{~cm}$ positions in the stone-hard-soil and the reference soil was ground to fine powders and fully wetted by de-ionized water for 24 hours before measuring to ensure dissolution of relevant species.

The same samples used for soil resistivity measurements were analysed by ionchromatography (IC) for concentrations of dissolved ions; $\mathrm{Cl}^{-}$and $\mathrm{SO}_{4}{ }^{2-}$ using a Thermo Scientific ICS-5000 IC system. 


\section{WILEY-VCH}

A cut cross-section of the stone-hard-soil (Figure 1d) from the $0-1 \mathrm{~cm}$ position was extracted for further analysis. This region was of special interest with regards to the interfacial reactions between the pipe and the soil. It contained both a black/brown corrosion product, a white powdery phase and the surrounding soil phase. After embedding in epoxy resin, a crosssection was prepared for analysis in SEM/EDS.

\section{Results}

The concentration of dissolved $\mathrm{Cl}^{-}$exceeded the measurement range for the IC equipment $>10$ g/L for both the stone-hard-soil and the reference soil, i.e. very high for soil in general. The concentration of sulphate, $\mathrm{SO}_{4}{ }^{2-}$ in the stone hard soil was $1.385 \mathrm{~g} \mathrm{~L}^{-1}$ in the stone-hard soil and $6.354 \mathrm{~g} \mathrm{~L}^{-1}$ in the reference soil.

The chemical analysis made by both EDS and ICP-OES provides a profile through the stonehard-soil along the line indicated in Figure 1a. The results are presented in Figure 2, where the concentrations have been normalised with respect to the concentrations of the reference soil sample: C/CREF. This allows for an easy overview of the alterations in the chemical composition of the soil throughout the profile. If the C/CREF of a species is larger than 1, the local concentration has increased and vice versa. Figure $2 \mathrm{a}$ and $\mathrm{b}$ or c and $\mathrm{d}$ are essentially showing the same results, but discrepancies arise from measurement errors from either method. The reference soil concentrations are given in Table 1. Not all elements can be detected by either method, i.e. $\mathrm{Cl}$ and $\mathrm{O}$ cannot be detected by ICP-OES, but conversely the ICP-OES technique is more sensitive and will detect species of low concentrations. Several elements, i.e. $\mathrm{H}$ and $\mathrm{C}$ cannot be detected by any of the methods, but the ICP-OES results account for only $41.4 \%$ of the total tested material (not including O for the ICP-OES) and thus many of the species may exist as oxides, hydroxides, carbonates, etc. which may be detected by other methods. 


\section{WILEY-VCH}

As expected, Fe concentrations are markedly increased in the close vicinity of the corrosion site (Figure 2a-b). The same is true for the alloying elements of the steel: $\mathrm{Mn}$ and V even though in very small quantities, verifying that this is indeed caused by steel corrosion. A general increase of both $\mathrm{Na}$ and $\mathrm{Cl}$ towards the corrosion site is observed, indicating a higher concentration of halite, $\mathrm{NaCl}$ (salt) in the stone-hard-soil compared to the reference soil. The concentration profiles of the earth alkaline ions $\mathrm{Ca}$ and $\mathrm{Mg}$ appear to be inverted, i.e. towards the corrosion site, $\mathrm{Mg}$ is high and Ca is low. At 1-2 cm Ca increases but Mg decreases. From 4-8 $\mathrm{cm} \mathrm{Mg}$ is dominant and finally at $10 \mathrm{~cm}$ the relationship is again inverted. The proportions between $\mathrm{Ca}$ and $\mathrm{Mg}$ is not 1:1 as is clear from Table 1, but their inverse relationship is very interesting and will be elaborated on further in the discussion. Several of the elements show reduced concentrations close to the corrosion site $(\mathrm{Na}, \mathrm{Cl}, \mathrm{Ca}, \mathrm{Si}, \mathrm{K}, \mathrm{Ti}$, Al) but this may simply be caused by a displacement of the original soil by the corrosion products emerging from the coating defect. Figure 3 shows the results of the XRD analysis on the samples taken along the profile shown in Figure 1a. The characteristic peaks of a series of species can be seen throughout the sample, but the intensity varies. Since the profiles were made under identical conditions, this may be interpreted as variations in the concentration along the profile, but not with respect to peaks of other species. (Q) quartz; $\mathrm{SiO}_{2}$, (C) calcite; $\mathrm{CaCO}_{3}$ and $(\mathrm{H})$ halite; $\mathrm{NaCl}$ is present throughout the sample and the reference soil, but the calcite and quartz signal is reduced towards the corrosion site. In the reference soil and the outer part of the stone-hard-soil a (D) dolomite; $\mathrm{CaMg}\left(\mathrm{CO}_{3}\right)_{2}$ phase is present. The XRD results support the findings of increased halite concentrations towards the corrosion site, especially in the 1-2 cm region in good correlation with the EDS and ICP-OES analysis in Figure 2. Close to the corrosion site in the $0-2 \mathrm{~cm}$ region, several new peaks emerge. Figure 4 shows an enhanced view of the $0-2 \mathrm{~cm}$ XRD spectra, and the new peaks are characterized as an aluminium substituted tobermorite: $\mathrm{Ca}_{5} \mathrm{Si}_{5} \mathrm{AlO}_{17}(\mathrm{OH}) \cdot 5 \mathrm{H}_{2} \mathrm{O}$, pyroaurite: 


\section{WILEY-VCH}

$\mathrm{Mg}_{6} \mathrm{Fe}_{2}(\mathrm{OH})_{16}\left(\mathrm{CO}_{3}\right)\left(\mathrm{H}_{2} \mathrm{O}\right)_{4.5}$ and a calcium iron vanadium oxide (civo): $\mathrm{Ca}_{3} \mathrm{Fe}_{3.5} \mathrm{~V}_{1.5} \mathrm{O}_{12}$. Some peaks, in the low $2 \theta$ angle region were still unidentified. Particularly the wider peaks are characteristic to clay species or phases with similar low crystallinity, and were generally consistent throughout the sample. Therefor they were not likely to have participated in the reactions and hence not of particular interest in this analysis. A markedly increased background signal in the $0-1 \mathrm{~cm}$ spectres caused by fluorescence with the $\mathrm{CuK} \alpha \mathrm{X}$-ray radiation indicates a strong enhancement of iron in these samples. An XRD spectrum of the white powder in Figure 1d has not been included here, but it was shown to consist of mainly (B) brucite; $\mathrm{Mg}(\mathrm{OH})_{2}$, as well as calcite and halite.

The $\mathrm{pH}$ measurements were conducted on 1:5 diluted soil to water weight samples, but since the $\mathrm{pH}$ is typically reported for a 1:1 dilution, the equivalent $\mathrm{pH}$ was calculated according to equation (2).

$\mathrm{pH}_{1: 1}=-\log \left(\frac{10^{-\mathrm{pH}_{1: 5}}}{5}\right)$

The obtained values are shown in Figure 5, giving a clear indication of alkalisation of the stone-hard-soil compared to the reference soil $\mathrm{pH}$. While the reference soil is already quite alkaline at $\mathrm{pH}=9.8$, the stone-hard-soil is as high as $\sim 12,1 \mathrm{~cm}$ from the corrosion site. Given that the alkalinity is caused by the cathode reaction (1) at the coating defect, and observing the general increase in $\mathrm{pH}$ from $10 \mathrm{~cm}$ to $1 \mathrm{~cm}$, it is anticipated that the $\mathrm{pH}$ at the $0 \mathrm{~cm}$ location may have been well beyond 12 .

Soil resistivity measurements of the stone-hard-soil and the reference soil yielded very low resistivities of only $\rho=0.3 \Omega \mathrm{m}$ for both, i.e. values comparable to seawater. This is a large part of the explanation to why the pipeline corroded, even at mitigated AC levels. Assuming a circular coating defect of diameter $30 \mathrm{~mm}$ (conservative), the area specific spread resistance for the coating defect, $\mathrm{R}_{\mathrm{S}}$, becomes

$\mathrm{R}_{\mathrm{S}}=\frac{\rho}{2 d} A=3.5 \cdot 10^{-3} \Omega \mathrm{m}^{2}$ 


\section{WILEY-VCH}

Even at just $1 \mathrm{~V}$ AC (conservative) this yields a current density far beyond the critical $\mathrm{J}_{\mathrm{AC}}=$ $30 \mathrm{~A} \mathrm{~m}^{-2}$ specified by EN 15280:2013.

$$
\mathrm{J}_{\mathrm{AC}}=\frac{\mathrm{U}_{\mathrm{AC}}}{\mathrm{R}_{\mathrm{S}}}=285 \mathrm{~A} \mathrm{~m}^{-2}
$$

The low soil resistivity is attributed to the high salt content measured by EDS and ICP-OES. In Figure 6, a cross-sectional view of the stone-hard-soil within $\sim 1 \mathrm{~cm}$ from the corrosion site is shown. The cut is made along the line indicated in Figure 1d. The cross-section clearly shows distinct phases in terms of visual appearance. A black/brown phase is visible at the corrosion site in the lower right corner (ZONE 1), surrounded by a more red/orange phase (ZONE 2). The colouration is assumed to be caused by dissolved iron and corrosion products. A white phase is present just left of the corrosion products and towards the pipe surface in the bottom of the image (ZONE 3). Then a concentric region of dark grey matter with numerous cracks is present (ZONE 4), and finally a bright beige region which extends to the rest of the stone-hard-soil in terms of appearance (ZONE 5). Towards the pipe surface in the bottom of the image a flat pattern indicates that the stone-hard-soil at some point detached partially from the pipe, and the resulting gap was filled with corrosion products and the white powdery phase identified as $\mathrm{Mg}(\mathrm{OH})_{2}$. This observation is supported by the circular pattern of the white phase observed in Figure 1c. Three areas within relatively homogeneous areas in the surrounding soil are marked (1-3) for chemical analysis by EDS. Furthermore a larger area across the black/brown, red and white region (ZONE 1-3) is chosen for element mapping by EDS.

EDS mapping of the marked area in Figure 6 can be seen in Figure 7 along with a closer look on some spherical structures observed in a cavity of the corrosion products, shown in secondary electron images (SEI). The EDS maps shows readings of the respective elements as white spots, that clearly maps out where the respective elements are present. The white phase clearly consists of mainly $\mathrm{Mg}$ and $\mathrm{O}$ in a 1:2 relationship read by a point EDS analysis, 


\section{WILEY-VCH}

corresponding to $\mathrm{Mg}(\mathrm{OH})_{2}$. Fe and $\mathrm{O}$ is present in the corrosion products. The spherulitic structure may be characteristic for siderite, $\mathrm{FeCO}_{3}$ or magnetite, $\mathrm{Fe}_{3} \mathrm{O}_{4}$. [17] Magnetite is a known corrosion product in AC corrosion cases, but the EDS investigation in the area marked on one sphere in Figure 7 suggested an Fe to $\mathrm{O}$ atomic ratio close to 1:3, thus suggesting $\mathrm{FeCO}_{3}$. The civo $\left(\mathrm{Ca}_{3} \mathrm{Fe}_{3.5} \mathrm{~V}_{1.5} \mathrm{O}_{12}\right)$ detected in the XRD spectra (Figure 4) may also be an option, since the mapping did show Ca present within the corrosion products, however the point analysis showed only minor Ca concentrations and no vanadium. Since no XRD verification of the corrosion product was possible, no conclusions could be made. Due to handling of the sample in aerated conditions and the likely oxidation of $\mathrm{Fe}(\mathrm{II})$ species as previously mentioned, a true characterization of the iron oxides formed under corrosion conditions is not possible.

The EDS measurements from locations 1-3 in Figure 6 i.e. in the vicinity of the corrosion site are shown in Figure 8. By comparison to the reference soil, it is evident that the concentration profiles of the species are matching (but suppressed due to the EDS results being relative), except for $\mathrm{Na}$ and $\mathrm{Cl}$ at location 1 and 2, and $\mathrm{Mg}$ in location 3. This is interpreted as enrichment of halite and brucite in these locations respectively, in line with the EDS mapping in Figure 7, however together with a clear trace of the original soil. These localised, but markedly different results within 0-1 cm from the corrosion site suggest that the chemical profile made by EDS and ICP-OES as well as XRD may be overly simplified, especially in this local region towards the coating defect. I.e. no brucite was detected along the XRDprofile in Figure 3, which may simply be explained by the fact that brucite appears locally, and was by chance not present in any of the profile samples in detectable amounts.

\section{Discussion}




\section{WILEY-VCH}

In Figure 9, Pourbaix diagrams for Fe, Ca and Mg are shown. They are calculated using the HSC Chemistry $5 \mathrm{E}$-pH software at $25^{\circ} \mathrm{C}$ and 1 bar pressure. In Figure 9a it can be seen that iron contains a small corrosive region at high $\mathrm{pH}$ where it may dissolve as $\mathrm{HFeO}_{2}{ }^{-}$, often suspected to play a role in the AC corrosion mechanism. This is highly dependent on the concentration of Fe in solution, and is often pictured differently in literature. The Ca diagram shows a large calcite region from neutral to highly alkaline $(\mathrm{pH} \approx 13)$ conditions. If the presence of $\mathrm{Mg}$ in the same system is considered, a smaller dolomite region appears. Interestingly, the reference soil $(\mathrm{pH}=9.8)$ and the $10 \mathrm{~cm}$ position showed dolomite traces in the XRD (Figure 3), but as $\mathrm{pH}$ in the stone-hard-soil rises to $\mathrm{pH}>11$ towards the centre (Figure 5) this disappears, corresponding nicely to the calculated stability region of dolomite in Figure 9b. As the $\mathrm{pH}$ further increases towards the centre, the quartz and calcite XRD signals are drastically reduced. This may be due to alkaline dissolution of these species, allowing for the formation of a tobermorite $\mathrm{Ca}_{5} \mathrm{Si}_{5} \mathrm{Al}(\mathrm{OH}) \mathrm{O}_{17} \cdot 5 \mathrm{H}_{2} \mathrm{O}$-phase consuming the dissolved $\mathrm{Ca}$ and $\mathrm{Si}$ ions as well as the produced $\mathrm{OH}^{-}$. Dissolution of quartz at high $\mathrm{pH}$ is known in literature. [18] The disappearance of calcite is in line with the observations by Stalder and suggests a pH value in the very center of the stone-hard-soil well above 13, confer Figure 9b, which could not be measured using conventional pH measurements in Figure 5. [8] The formation of tobermorite in highly alkaline environments is well known from investigations of the effect of an alkaline plume from nuclear waste concrete containers on natural clays containing both Ca and Si. [19] Others have synthesized an aluminium substituted tobermorite from oil shale ash containing among others both calcite and quartz in an alkaline $(\mathrm{pH}=14.9)$ hydrothermal $\left(160^{\circ} \mathrm{C}\right)$ process. [20] Tobermorite formation is generally effected by the silica source and addition of $\mathrm{Al}$, as well as $\mathrm{pH}$, and may contribute positively to a soils cation exchange capacity (CEC) i.e. its ability to accumulate cations such as $\mathrm{H}^{+}, \mathrm{Al}^{+}, \mathrm{Ca}^{+}$and $\mathrm{Mg}^{+}$. [21] Geologically, tobermorite is usually formed by metamorphism, 


\section{WILEY-VCH}

i.e. at elevated temperatures or pressure in calcite containing rocks, and thus it may be a tracer for elevated temperatures towards the coating defect possibly caused by high alternating current densities.

Pyroaurite, $\mathrm{Mg}_{6} \mathrm{Fe}_{2}(\mathrm{OH})_{16}\left(\mathrm{CO}_{3}\right)\left(\mathrm{H}_{2} \mathrm{O}\right)_{4.5}$, was synthesized in a near neutral $\mathrm{pH}$ to high $\mathrm{pH}$ environments by Hansen and Taylor. [22] They found that in high pH environment a possible formation path was via slow addition of Fe(II) to Mg-rich phases, e.g. brucite or magnesite, $\mathrm{MgCO}_{3}$. When saturated with water, and upon the reaction with oxygen, Fe(II) may oxidize to Fe(III) and react with Mg species in solution. While the environment under cathodic protection is depleted of oxygen, it is possible that the presence of an alternating voltage may alternate the oxidation step of available iron from $\mathrm{Fe}(\mathrm{II})$ to $\mathrm{Fe}(\mathrm{III})$ during the anodic halfwave, and in that way provide the conditions for pyroaurite formation. [23] The observation of pyroaurite may be an indicator for the rigth conditions for formation of green rust which is also a layered double hydroxide and is found on carbon steel under cathodic protection. [24] The intertwining relation between $\mathrm{Ca}$ and $\mathrm{Mg}$ in the stone-hard-soil may be explained by dissolution of the present dolomite and calcite phases in the original soil making $\mathrm{Ca}$ and $\mathrm{Mg}$ ions mobile in the soil. Even at slightly elevated $\mathrm{pH}$ brucite may precipitate (Figure 9c), and as it appears on the interface between pipe and stone-hard-soil in Figure 1c and the crosssection in Figure 6 this phase may fill out cavities and cracks formed, especially close to the corrosion site causing the $0-1 \mathrm{~cm} \mathrm{Mg}$ rise. Pyroaurite formation may also play a role. The formed hydrogen gas from the cathode reaction (1) is likely to push the stone-hard-soil away from the steel or form pores or cracks, allowing the gas to escape. Furthermore, the extreme alkalisation from the cathode reaction (1) at the electrode/electrolyte interface will dissolve the calcite that may allow for the some of the Ca ions to migrate outwards in the stone-hardsoil and re-precipitate as calcite at slightly lower $\mathrm{pH}$ causing the 1-2 cm Ca rise. Other Ca ions participate in the formation of tobermorite. Even though calcite is present in the reference 


\section{WILEY-VCH}

soil, the XRD measurements show an increased amount in the stone-hard-soil, suggesting that some of the Ca in the reference soil may exist as soluble ions, and some as calcite and dolomite. Soluble Ca ions may migrate towards the stone-hard-soil structure as they are consumed here by calcite precipitation, causing the increase in Ca concentration at the $10 \mathrm{~cm}$ position. The elevated levels of calcite may very well contribute to the hardening of the soil. The potential field may also contribute to electro-kinetic cementation of the calcareous clayey soil at the cathode (and to a higher degree at the anode, however not investigated in this study) which might contribute substantially to the hardness of the stone-hard-soil. [25] The increased concentration of $\mathrm{NaCl}$ in the stone-hard-soil is not previously reported in literature, but may support Nielsen and Cohn's theory that the stone-hard-soil can act as an antenna of low soil resistivity that is able to pick up and discharge currents in the soil, since $\mathrm{NaCl}$ is easily soluble and may increase ionic conductivity. [6] The measured soil resistivity for both reference soil and the stone-hard-soil was as low as $0.3 \Omega \mathrm{m}$, and thus no difference could be measured. This is likely linked to the already high $\mathrm{NaCl}$ concentrations in the reference soil (Table 1 + IC results), and thus the effect of having a slightly higher salt concentration in the stone-hard-soil may be insignificant in terms of conductivity. In connection with the findings that a thin crevice had formed between the pipe and the stonehard-soil structure, the low resistivity further allows for a drastic alteration of the localised soil chemistry in this small crevice in the centre of the stone-hard-soil, because the surrounding dense sphere slows down diffusion of formed species at the corrosion site, e.g. $\mathrm{OH}^{-}$, while currents through the coating defect may actually be enhanced. Provided the stonehard-soil in dry conditions for the present analysis however, it is uncertain what the in situ resistivity has actually been, since it is highly influenced by the moisture content. This moisture content is expected to be influenced by the potential gradient field around the negatively charged pipe. It has been demonstrated that cathodic protection increases the 


\section{WILEY-VCH}

moisture content of the soil/steel interface in unsaturated soils. [24] The cathode will attract positive ions in solution, and thereby water by the process of electro-osmosis, since water molecules are attracted to the cations. [26] The reason for the enhanced $\mathrm{NaCl}$ concentration may be explained by this attraction of positively charged $\mathrm{Na}^{+}$ions in solution. This effect is illustrated in Figure 10. The negatively charged $\mathrm{Cl}^{-}$ions should be repelled by the cathodic pipe, but may follow the migration of cations to ensure local charge neutrality or simply follow the water which will continuously migrate towards the coating defect where it will be

consumed by the cathode reaction (1). The opposite observation for sulphate ions $\mathrm{SO}_{4}{ }^{2-}$ may be explained by higher charge of this larger anion that enhances the influence of the electric field and slows down diffusion, making it unable to follow the cations towards the coating defect. The effect of an alternating voltage, and thus changing direction of the electric field, on the migration of an- and cations respectively is unknown, but the net direction of current, i.e. towards the cathode, is expected to govern the direction of the water migration, and as it has been discussed, the cathodic current is enhanced by AC by the process of faradaic rectification.

\section{Conclusions}

The investigation of a stone-hard-soil formation from an AC corroded steel pipeline under cathodic protection in a Ca-rich soil has revealed a number of findings:

- The $\mathrm{pH}$ of the stone hard soil was high from $\sim 11$ in the entire sample to $>13$ close to the corrosion site, based on $\mathrm{pH}$ measurements and the evident dissolution of calcite, $\mathrm{CaCO}_{3}$, in the centre. Throughout the rest of the stone-hard-soil calcite levels were increased, compared to a reference soil sample, possibly contributing to the hardness of the structure. Dolomite, $\mathrm{CaMg}\left(\mathrm{CO}_{3}\right)_{2}$, having an upper stability limit of $\mathrm{pH} \approx 11$, 


\section{WILEY-VCH}

was present in the reference soil, but disappeared inwards in the stone-hard-soil, confirming the measured $\mathrm{pH}$ values.

- Tobermorite, $\mathrm{Ca}_{5} \mathrm{Si}_{5} \mathrm{Al}(\mathrm{OH}) \mathrm{O}_{17} \cdot 5 \mathrm{H}_{2} \mathrm{O}$, has formed close to the corrosion site where calcite and quartz, $\mathrm{SiO}_{2}$, have disappeared. This is evidence of a very high $\mathrm{pH}$ environment. The kinetics for formation may have been enhanced by joule heating of the pipe-soil interface caused by passing AC currents.

- Elevated concentrations of halite, $\mathrm{NaCl}$, in the stone-hard-soil were found and the soil resistivity measured as low as $0.3 \Omega \mathrm{m}$. Much dependent on the moisture content, this may contribute to the stone-hard-soil being a low resistivity path for currents entering the pipe at the coating defect, while at the same time the dense stone-hard-soil may hinder diffusion of chemical species away from the corrosion site and create a crevice environment. The high concentration of $\mathrm{NaCl}$ is interpreted as a result of electroosmosis of hydrated cations towards the cathodic coating defect, thus providing a high humidity and low resistivity environment.

- Brucite, $\mathrm{Mg}(\mathrm{OH})_{2}$, was found as a white powder phase, especially in cracks and cavities such as between the pipe and the stone-hard-soil. It is not estimated to contribute significantly to the hardness of the stone-hard-soil, but rather to be a filler material providing cohesiveness.

- The present analysis is made $>1$ year after excavation of the stone-hard-soil, which has formed over several years in the soil. The conditions around the corrosion site have undoubtedly changed on a daily, seasonally or yearly basis in terms of potentials and currents, wetness levels, temperature, alkalinity, etc. during the service life of the pipeline. It is not possible to link the formation of the stone-hard-soil to a set of welldefined process conditions, but the analysis is a valuable contribution to the discussion 


\section{WILEY-VCH}

about alkalisation and the establishment of a characteristic environment around a coating defect subject to AC corrosion.

\section{Acknowledgements}

The present work was done in collaboration between MetriCorr, DESFA and the Technical University of Denmark, DTU, and was financially supported by the Danish Innovation Fund.

\section{References}

[1] P. D. Simon, presented at NACE Northern Area Western Conference, Calgary, Alberta, 15 - 18 February, 2010.

[2] G. C. Christoforidis, D. P. Labridis, P. S. Dokopoulos, N. Kioupis, presented at CeoCor, Dresden, Germany, 2004.

[3] F. Stalder, Materials Science Forum, 1997, 247, [139-146].

[4] P. Linhardt, G. Ball, presented at CORROSION, San Diego, California, 12 - 16 March, 2006.

[5] R. Wakelin, R. Gummow, S. Segall, presented at CORROSION, San Diego, California, 22 - 27 March, 1998.

[6] L. V. Nielsen, P. Cohn, presented at CeoCor, Brussels, Belgium, 2000.

[7] F. Stalder, D. Bindschelder, Gas Wasser Abwasser, 1991, 71, [307-313].

[8] L. Di Biase, A.C. Corrosion on Cathodically Protected Pipeliness, CeoCor, Brussels, 2001.

[9] M. Büchler, C. H. Voûte, H. G. Schöneich, presented at CeoCor, Starý Smokovec, Slovakia, 20 - 23 May, 2008.

[10] L. V. Nielsen, P. Cohn, presented at CeoCor, Dresden, Germany, 2004.

[11] L. V. Nielsen, Technical University of Denmark \& DONG Natural Gas A/S, Kgs. Lyngby, Denmark, 2000.

[12] R. Bosch, W. Bogaerts, Corrosion Science, 1998, 40, [323-336].

[13] U. Bertocci, CORROSION-NACE, 1979, 35, [211-215].

[14] I. Ibrahim, B. Tribollet, H. Takenouti, M. Meyer, J. Braz. Chem. Soc., 2015, 26, [196208].

[15] I. Ibrahim, M. Meyer, H. Takenouti, B. Tribollet, J. Braz. Chem. Soc., 2016, 27, [605615].

[16] N. Kioupis, K. Maroulis, presented at 8th International Conference Pipeline Rehabilitation \& Maintenance, Istanbul, Turkey, 2006.

[17] X.-F. Qu, Q.-Z. Yao, G.-T. Zhou, Eur. J. Mineral, 2011, 23, [759-770].

[18] Y. Niibori, M. Kunita, O. Tochiyama, T. Chida, Journal of Nuclear Science and Technology, 2000, 37, [349-357]. 


\section{WILEY-VCH}

[19] P. Vieillard, S. Ramírez, A. Bouchet, A. Cassagnabère, A. Meunier, E. Jacquot, Applied Geochemistry, 2004, 19, [1699-1709].

[20] J. Reinik, I. Heinmaa, J. P. Mikkola, U. Kirso, FUEL, 2007, 86, [669-676].

[21] L. Li, Z. X. Wu, Y. X. Li, H. L. Sha, G. W. Song, Desalination and Water Treatment, 2014, 52, [4292-4297].

[22] H. C. B. Hansen, R. M. Taylor, Clay Minerals, 1990, 25, [161-179].

[23] M. Büchler, Materials and Corrosion, 2012, 63, [1181-1187].

[24] D. Nguyen Dang, L. Lanarde, M. Jeannin, R. Sabot, Ph. Refait, Electrochimica Acta, 2015, 176, [1410-1419]

[25] J. Shang, E. Mohammedelhassan, M. Ismail, Can. Geotech. J., 2004, 41, [877-893].

[26] L. G. Adamson, G. V. Chilingar, C. M. Beeson, R. A. Armstrong, Eng. Geol., 1966, 1, [291-304]. 


\section{WILEY-VCH}
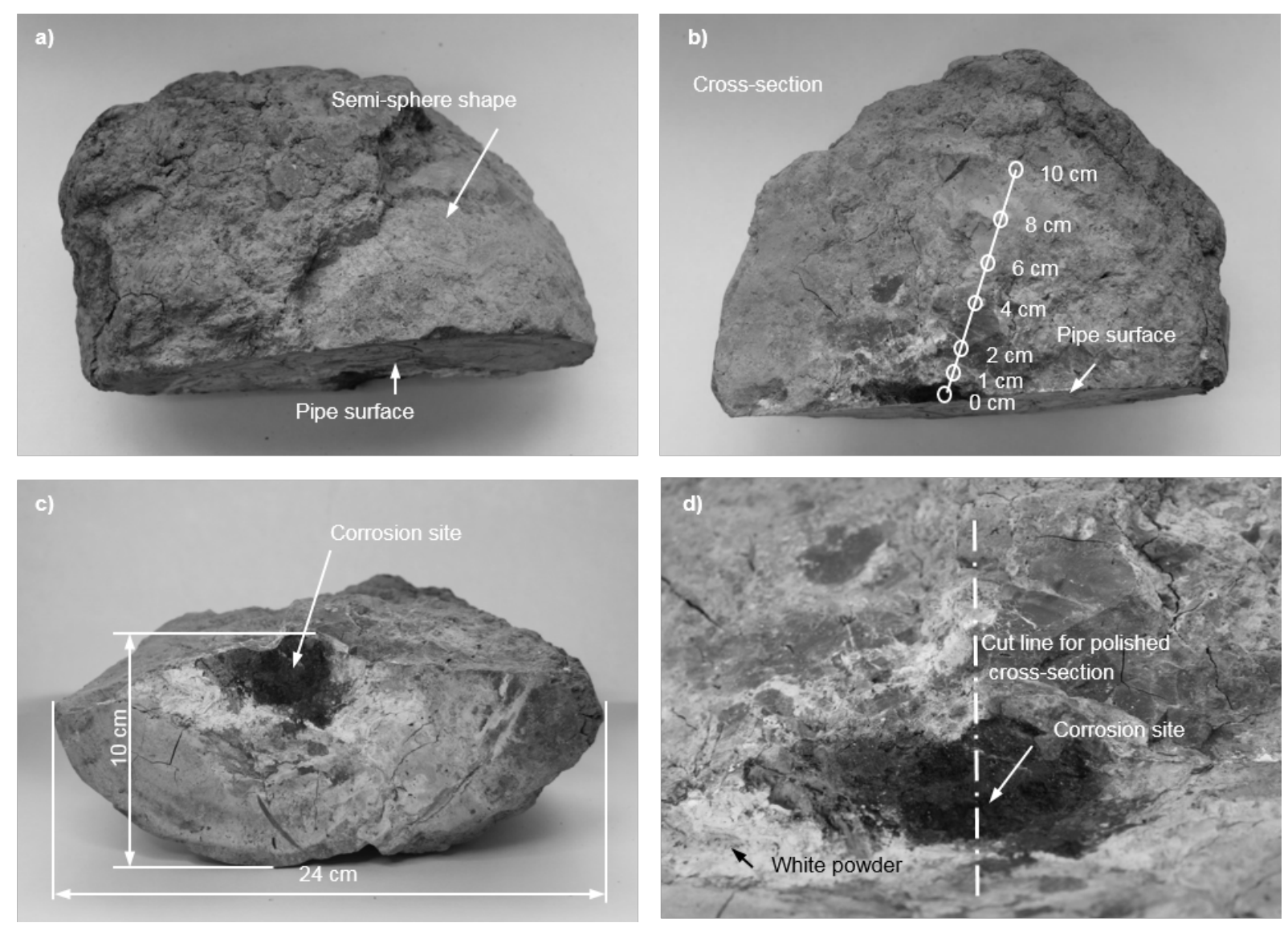

Figure 1. Stone-hard-soil semi-sphere from an AC corrosion case on a metallic pipeline. a)

Cross-section with indications of sites for taking samples for further analysis. b) View of the outer surface of the sphere. c) View from the pipe surface with the corrosion site clearly visible and dimensions as shown. d) Close up of corrosion site surrounded by a white powder. The cut line for making a polished cross-section is indicated. 
WILEY-VCH

a)

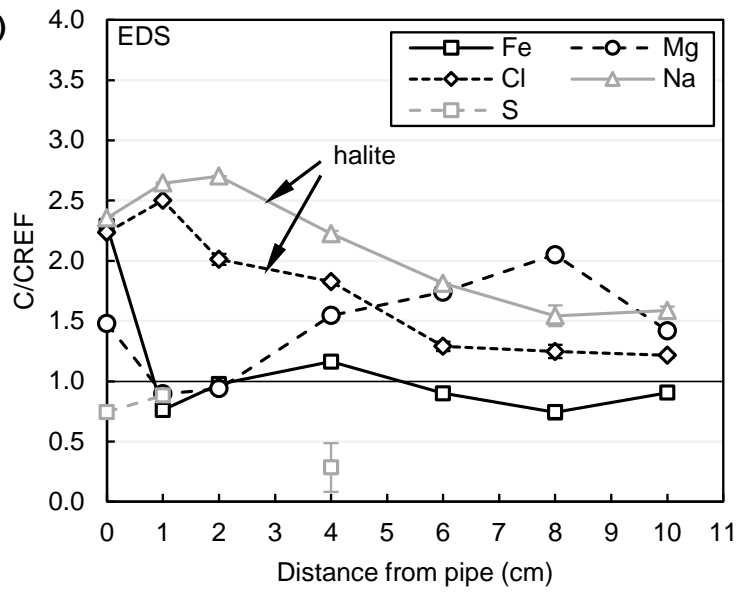

c)

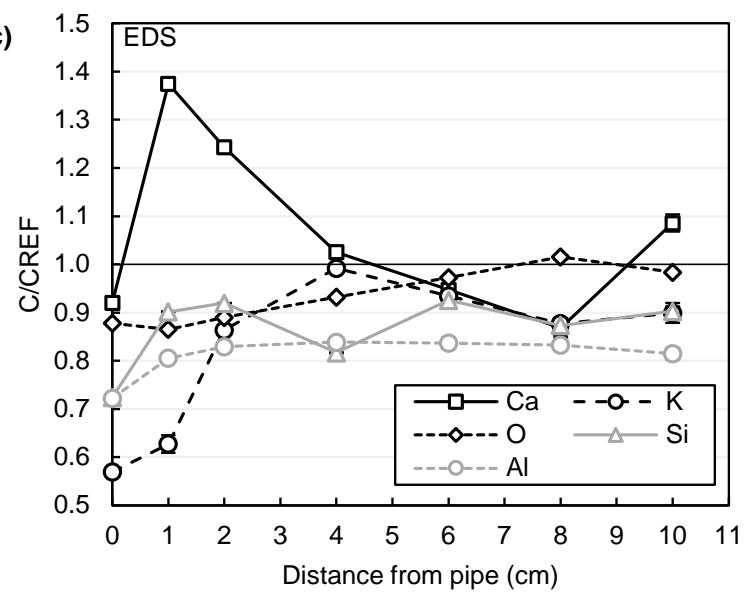

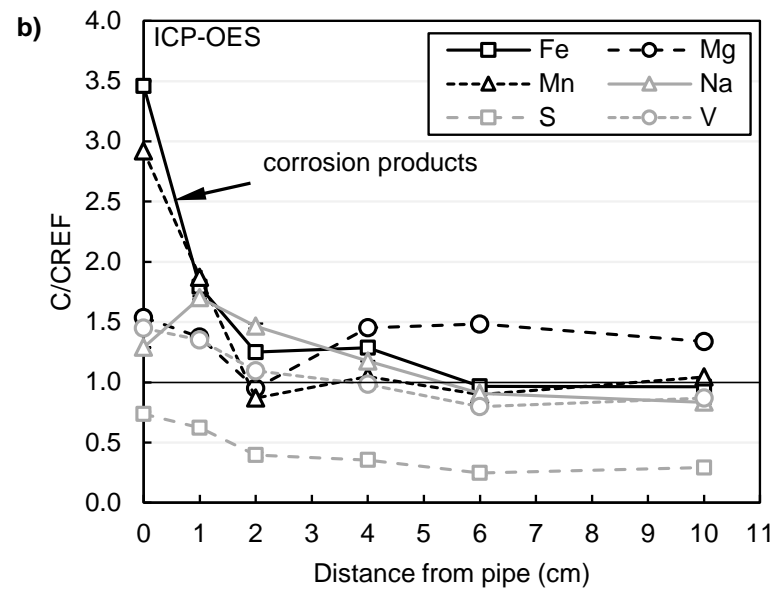

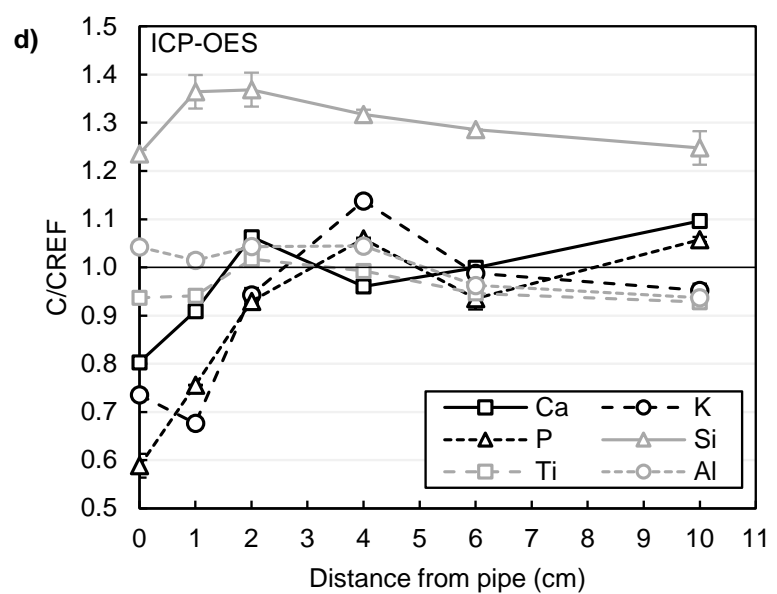

Figure 2. Chemical analysis for various elements using EDS (a,c) and ICP-OES (b,d). Results are displayed relative to analysed values of the reference soil sample. Not all elements can be found with either method. 


\section{WILEY-VCH}

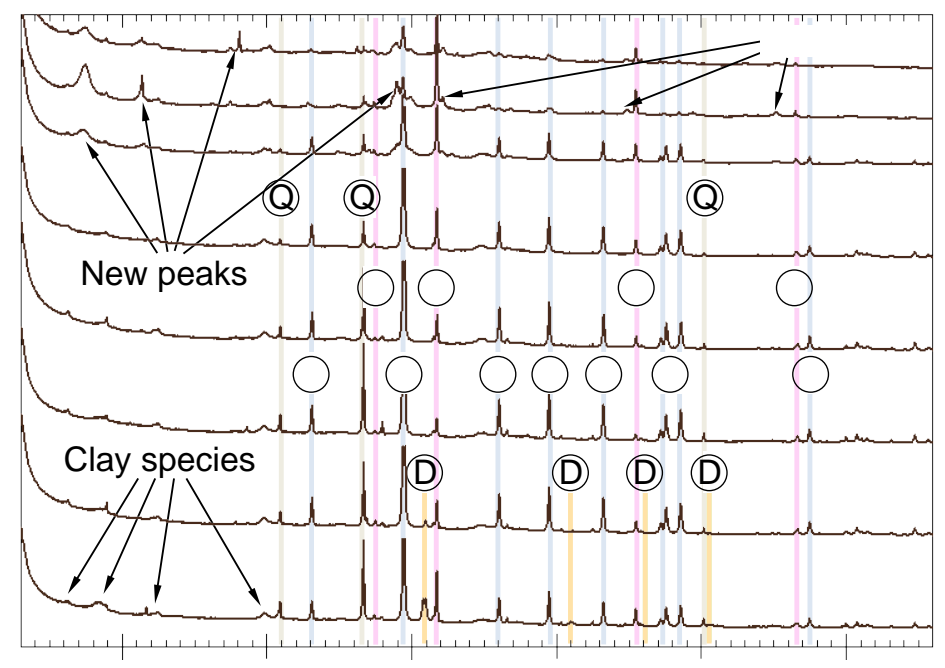

Figure 3. XRD $(\mathrm{CuK} \alpha)$ spectra of the profile samples showing appearance of different species through the stone-hard-soil sample: (Q) Quartz $\mathrm{SiO}_{2}$, (H) Halite $\mathrm{NaCl}$, (C) Calcite $\mathrm{CaCO}_{3}$, (D) Dolomite $\mathrm{CaMg}\left(\mathrm{CO}_{3}\right)_{2}$. 


\section{WILEY-VCH}

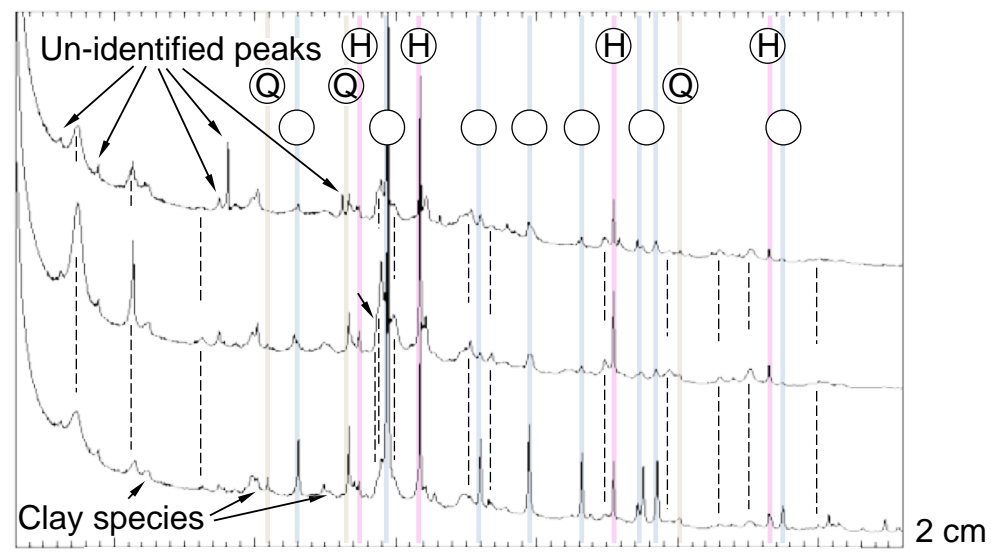

Figure 4. XRD $(\mathrm{CuK} \alpha)$ spectra of the $0-2 \mathrm{~cm}$ samples where the $(\mathrm{C})$ calcite and $(\mathrm{Q})$ quartz peaks are dramatically reduced and new peaks appear for an aluminium substituted (T) tobermorite $\mathrm{Ca}_{5} \mathrm{Si}_{5} \mathrm{Al}(\mathrm{OH}) \mathrm{O}_{17} \cdot 5 \mathrm{H}_{2} \mathrm{O}$, (P) pyroaurite $\mathrm{Mg}_{6} \mathrm{Fe}_{2}(\mathrm{OH})_{16}\left(\mathrm{CO}_{3}\right)\left(\mathrm{H}_{2} \mathrm{O}\right)_{4.5}$ and $(\mathrm{V})$ calcium iron vanadium oxide (civo) $\mathrm{Ca}_{3} \mathrm{Fe}_{3.5} \mathrm{~V}_{1.5} \mathrm{O}_{12}$. These new phases consume some of the dissolved $\mathrm{Ca}$ and $\mathrm{Si}$, as well as $\mathrm{Fe}, \mathrm{Al}$ and $\mathrm{Mg}$. Vanadium is a minor alloying element in API 5L steels. 


\section{WILEY-VCH}

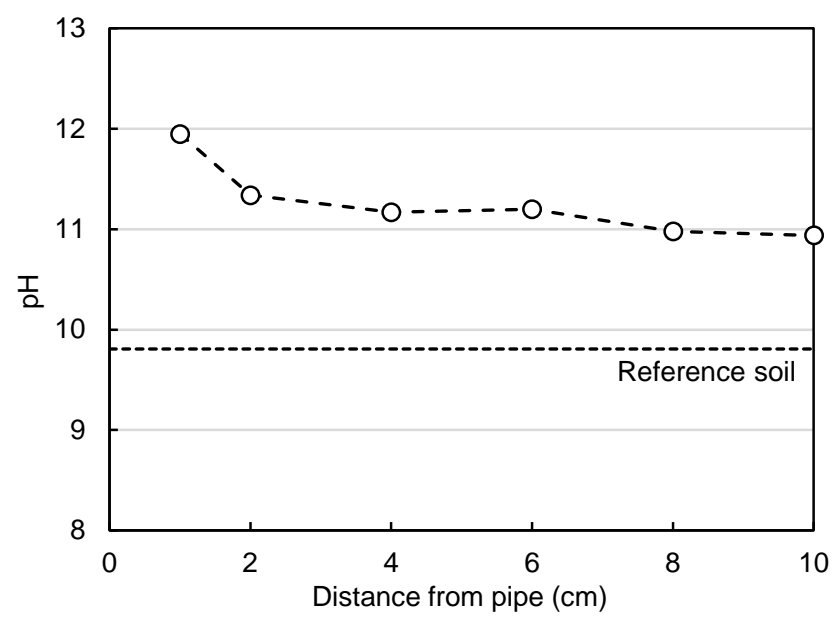

Figure 5. $\mathrm{pH}$ profile as a function of the distance from the pipe together with the reference soil $\mathrm{pH}$ level. The results clearly indicate alkalisation of the stone-hard-soil, especially close to the cathodic pipe. 


\section{WILEY-VCH}

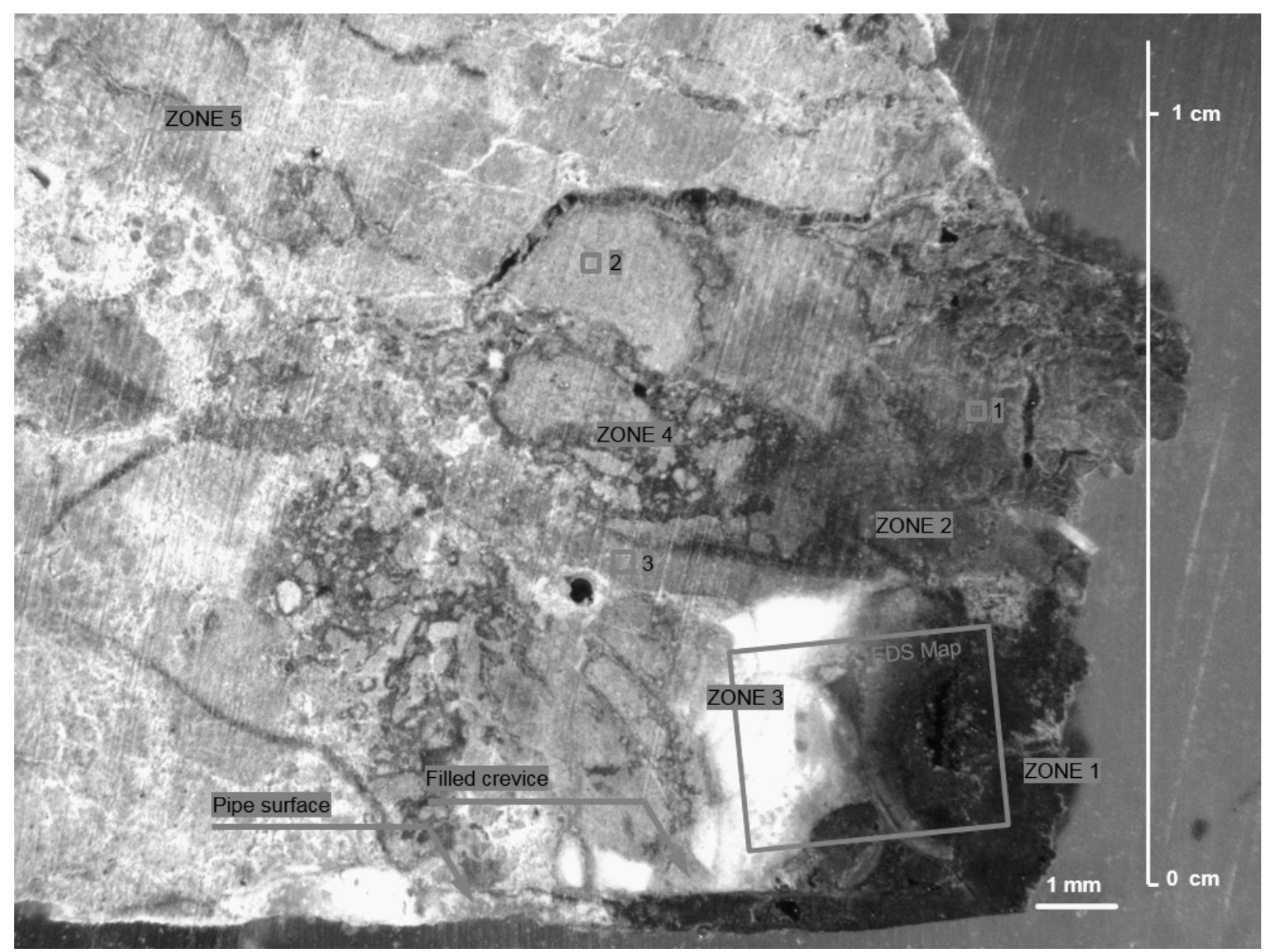

Figure 6. Cross-section of the stone-hard-soil close to the corrosion site in the lower right

corner $(0-1 \mathrm{~cm})$, moulded in epoxy resin. Marked areas were investigated with EDS, see

Figure 7 and Figure 8. 


\section{WILEY-VCH}
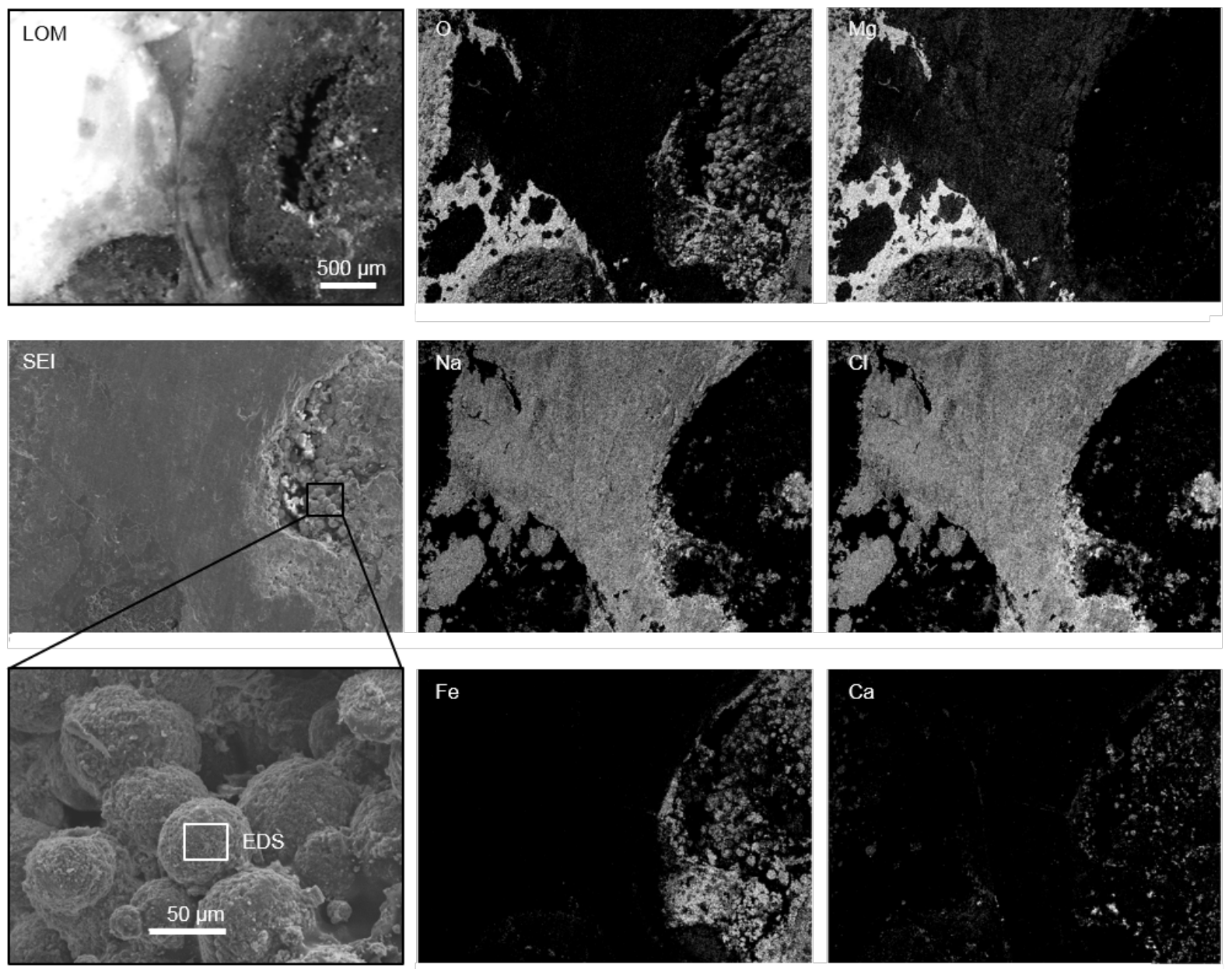

Figure 7. Close investigation of polished cross-section (Figure 6). Upper left: LOM image.

Middle left: SEM image. Lower left: Close-up of corrosion products including area of detailed EDS analysis. Rest: EDS maps of the respective elements as indicated, showing distinct phases $(\mathrm{Mg}+\mathrm{O}, \mathrm{Na}+\mathrm{Cl}, \mathrm{Fe}+\mathrm{O}, \mathrm{Ca}+\mathrm{O})$ around the corrosion site. 


\section{WILEY-VCH}

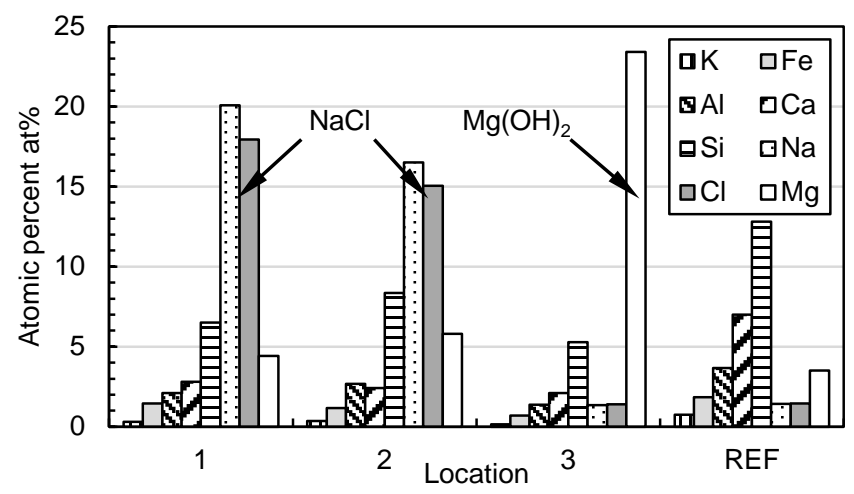

Figure 8. EDS results of locations 1-3 (Figure 6) and comparison to the reference soil.

Location 1 and 2 are strongly enriched with Halite, $\mathrm{NaCl}$, while location 3 is enriched with Brucite, $\mathrm{Mg}(\mathrm{OH})_{2}$. 

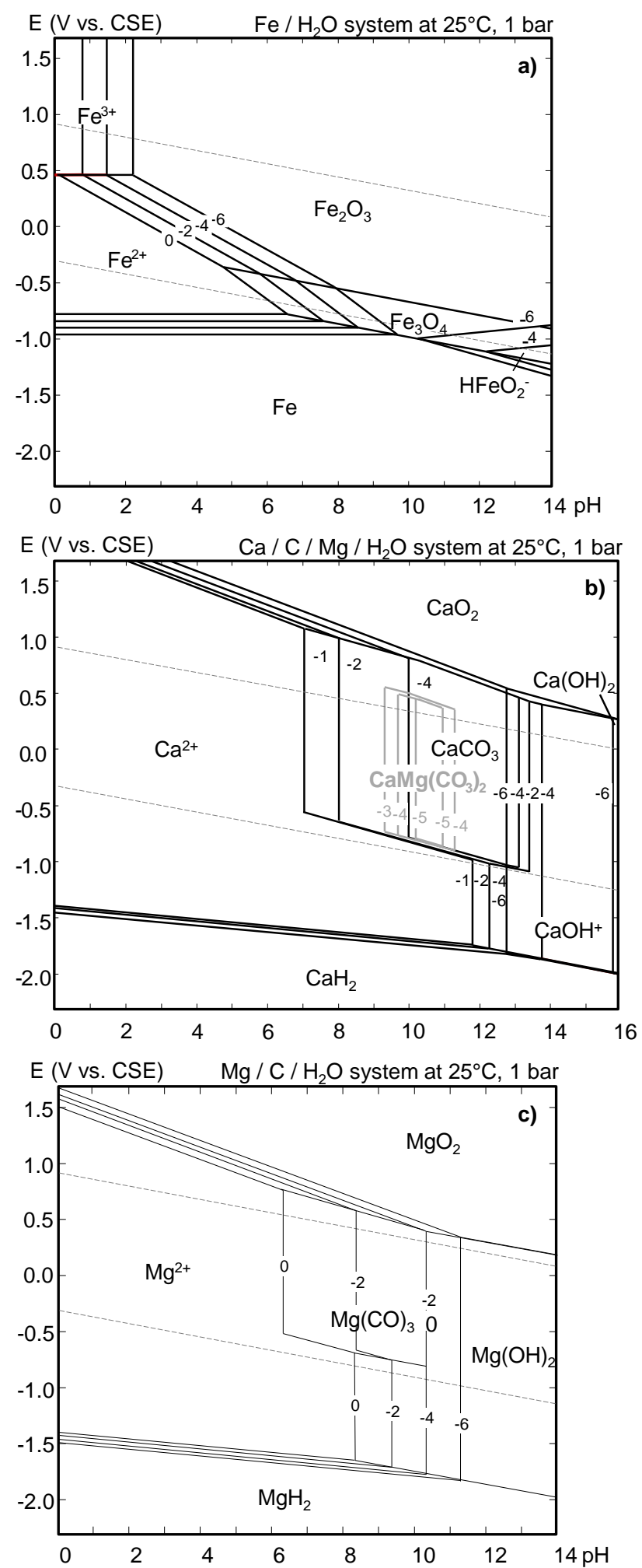

Figure 9. Calculated Pourbaix diagrams for the $\mathrm{Fe} / \mathrm{H}_{2} \mathrm{O}$ (a), $\mathrm{Ca} / \mathrm{C} / \mathrm{Mg} / \mathrm{H}_{2} \mathrm{O}$ (b) and $\mathrm{Mg} / \mathrm{C} / \mathrm{H}_{2} \mathrm{O}$ (c) system at $25^{\circ} \mathrm{C}$ and 1 bar pressure. a) The corrosive regions at high and low $\mathrm{pH}$ increases with lower concentrations of Fe. b) The molality of $\mathrm{C}$ was given as $10^{-4}$, while the molality of $\mathrm{Ca}$ is variable. The $\mathrm{CaCO}_{3}$ (calcite) region can be seen to appear at $\geq 10^{-}$ 


\section{WILEY-VCH}

${ }^{4} \mathrm{~mol} / \mathrm{kg}$ Ca. Higher $\mathrm{C}$ concentrations further stabilizes the $\mathrm{CaCO}_{3}$ region. If $\mathrm{Mg}$ is present (10${ }^{5} \mathrm{~mol} / \mathrm{kg}$ ), a small $\mathrm{CaMg}\left(\mathrm{CO}_{3}\right)_{2}$ (dolomite) region is outlined in gray and growing with increasing Ca molality. c) Brucite, $\mathrm{Mg}(\mathrm{OH})_{2}$, is stable at elevated $\mathrm{pH}$ but very dependent on the concentration. 


\section{WILEY-VCH}

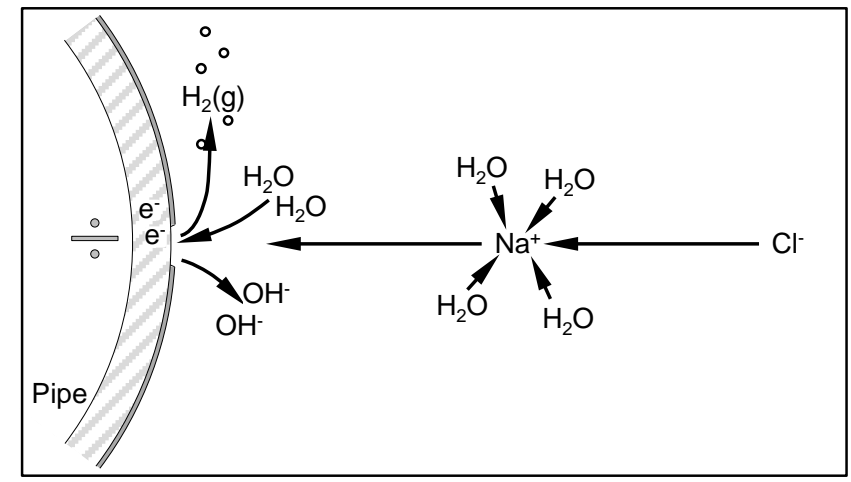

Figure 10. Simplified alkalisation and electro-osmosis illustration. Hydrated $\mathrm{Na}^{+}$is attracted by the negatively charged pipe. At the surface, the cathode reaction (1) produces $\mathrm{OH}^{-}$. $\mathrm{Cl}^{-}$ions follow the flow of $\mathrm{Na}^{+}$to conserve local charge neutrality. The increase in ion concentration reduces the local soil resistivity and enhances the cathode reaction. 


\section{WILEY-VCH}

Table 1. Concentration of species in the reference soil sample measured by EDS or ICP-OES.

\begin{tabular}{lccccccccccccccc}
\hline & $\mathrm{Fe}$ & $\mathrm{Mg}$ & $\mathrm{Cl}$ & $\mathrm{Mn}$ & $\mathrm{Na}$ & $\mathrm{S}$ & $\mathrm{V}$ & $\mathrm{Ca}$ & $\mathrm{K}$ & $\mathrm{O}$ & $\mathrm{P}$ & $\mathrm{Si}$ & $\mathrm{Ti}$ & $\mathrm{Al}$ & $\mathrm{Sum}$ \\
\hline $\begin{array}{l}\text { EDS } \\
(\% w t)\end{array}$ & 5.1 & 4.1 & 2.6 & - & 1.6 & 0.4 & - & 13.3 & 1.6 & 49.6 & - & 17.0 & - & 4.8 & 100 \\
$\begin{array}{l}\text { ICP-OES } \\
(\mathrm{dg} / \mathrm{kg})\end{array}$ & 2.7 & 4.4 & - & 0.07 & 2.8 & 0.1 & 0.01 & 19.2 & 0.9 & - & 0.02 & 8.1 & 0.2 & 2.9 & 41.4 \\
\hline
\end{tabular}




\section{WILEY-VCH}

\section{Graphical Abstract}

A stone-hard-soil structure, characteristic for AC corrosion of pipelines is analysed. The $\mathrm{pH}$ of the stone-hard-soil was high from $~ 11$ in the entire sample to $>13$ close to the corrosion site. Elevated concentrations of halite, $\mathrm{NaCl}$, in the stone-hard-soil was found. This is suspected to create a low resistivity path for AC and DC currents. Hardening of the stonehard-soil may be caused by precipitation of calcite and possibly electro-kinetic cementation. The soil resistivity was as low as $0.3 \Omega \mathrm{m}$ which is the main reason for AC corrosion due to high AC current densities even at mitigated AC voltage levels. Formation of cement-like minerals such as pyroaurite and tobermorite close to the coating defect is evidence of a very high $\mathrm{pH}$.

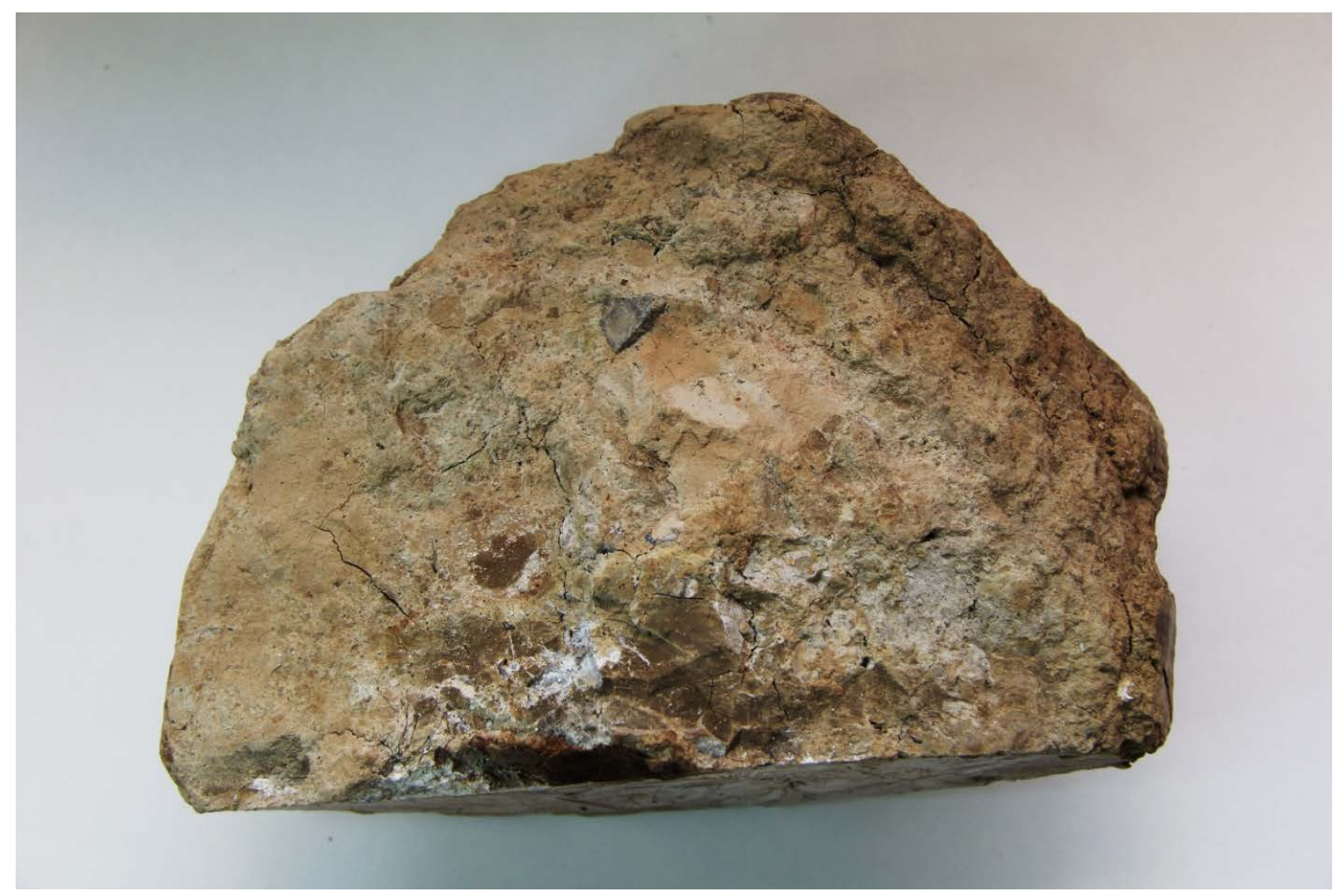

